\title{
Modular Power Supply for Micro Resistance Welding
}

\author{
Oleksandr Bondarenko* (Postdoctoral Researcher, National Technical University of Ukraine "Igor Sikorsky Kyiv \\ Polytechnic Institute"), Ievgen Verbytskyi (Associate Professor, National Technical University of Ukraine "Igor \\ Sikorsky Kyiv Polytechnic Institute”), Vadym Prokopets (Associate Professor, Taras Shevchenko National University \\ of Kyiv ), Oleksandr Kaloshyn (PhD Student, National Technical University of Ukraine "Igor Sikorsky Kyiv \\ Polytechnic Institute"), Denys Spitsyn (MSc Student, National Technical University of Ukraine "Igor Sikorsky Kyiv \\ Polytechnic Institute"), Tetiana Ryzhakova (MSc Student, National Technical University of Ukraine "Igor Sikorsky \\ Kyiv Polytechnic Institute"), Yuliia Kozhushko (MSc Student, National Technical University of Ukraine "Igor \\ Sikorsky Kyiv Polytechnic Institute")
}

\begin{abstract}
The study is devoted to the important issue of enhancing the circuitry and characteristics of power supplies for micro resistance welding machines. The aim of the research is to provide high quality input current and to increase the energy efficiency of the output pulse generator by means of improving the circuit topologies of the power supply main blocks. In study, the principle of constructing the power supply for micro resistance welding, which provides high values of output welding current and high accuracy of welding pulse formation, makes it possible to reduce energy losses, and provides high quality of consumed input current, is represented. The multiphase topology of the charger with power factor correction based on SEPIC converters is suggested as the most efficient for charging the supercapacitor storage module. The multicell topology of the supercapacitor energy storage with voltage equalizing is presented. The parameters of the converter cells are evaluated. The calculations of energy efficiency of the power supply's input and output converters based on suggested topologies are carried out and verified in MATLAB Simulink. The power factor value greater than $99 \%$ is derived.
\end{abstract}

Keywords - Energy efficiency; Modular multilevel converters; Power supplies; Supercapacitors; Welding.

\section{INTRODUCTION}

One of the most effective ways of permanent joining of small-scale metal parts is resistance welding. The joints are formed by heating the welded parts in required spots to the melting point with electric current, which is passed through them. The amplitude of welding current is in the range of hundreds of amperes to several kiloamperes and depends on the material and thickness of the welded parts. The energy for welding is consumed by pulses duration of which is very short comparing to the duration of the pauses between them and can range from one to dozens of milliseconds [1], [2]. A very important characteristic of the welding pulse is its form. The pulse must consist of smooth rise and fall and a flat top. The use of appropriate pulse form for specified welding conditions is critical for obtaining the high quality welded joints.

The power supply of welding equipment is responsible for generating the welding pulse of the required form and power.
The energy efficiency of welding equipment is determined also by technical parameters of the power supply.

In terms of design principles, the power supplies for resistance welding may be divided into two large groups: with direct power consumption from electrical grid - Direct Energy Type, and with intermediate energy storage - Energy Storage Type [2]-[4]. The first one largely affects the electrical network and has low energy efficiency. The second one gives the possibility to use the power supply off-line for some time, and affects the network much softer [4]. That is why the second one is more widely used recently [4]-[8].

The systems based on the energy storage topology usually have more complicated structure and require the use of the multicell-type storage with low internal resistance and high energy capacity, such as supercapacitors. This type of power supplies makes it possible to increase the power factor up to nearly " 1 " in case when the power factor corrector (PFC) is used as a charging device. Different converter topologies may be used to design PFC, for example, basic topologies like buck, boost, buck-boost or topologies SEPIC, ZETA, Cuk of single or multiphase types. The choice of specific topology of the input converter for resistance welding system is determined by its efficiency in the modes that are typical for the output converter.

The output converter is the welding pulse generator. It is the most important part of the power supply for micro resistance welding. It directly regulates the welding current in load and determines welding modes. There are some effective decisions for constructing the welding pulse generator that are based on using modular (multicell) principle [9]. The modular principle makes it possible to obtain high values of load current by combining a number of identical cells rated on relatively low currents. It also helps to improve the form of the current or voltage curve, increases flexibility in converter restructuring, provides a high level of design unification, and expands opportunities for improving the reliability of the converter by reserving the cells.

\footnotetext{
Corresponding author.

E-mail: bondarenkoaf@gmail.com
} 
The aim of the research is to provide high quality of input current and to increase the energy efficiency of the output pulse generator by means of improving the circuit topologies of power supply main blocks.

\section{GENERALIZED BLOCK DIAGRAM OF THE POWER SUPPLY}

The generalized block diagram of the power supply for micro resistance welding is shown in Fig. 1.

The blocks of the power supply perform the following functions. The input converter provides the energy necessary for welding. It is represented in Fig. 1 in two variants: charger + energy storage (Energy Storage Type) or matching transformer + rectifier (Direct Energy Type). For the considered power supply the first variant was chosen. The pulse generator provides current pulses for the load, according to the required profile specified by the control system. The parameters of welding pulses are controlled during the welding process with feedback signals from the sensors in the load.

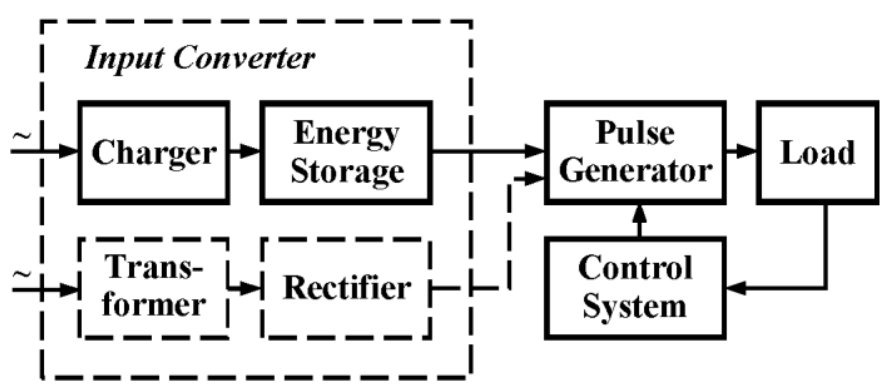

Fig. 1. Generalized block diagram of the power supply for micro resistance welding.

In the next sections, the circuit topologies of main blocks of the power supply are suggested and their operation principles are described.

\section{THE CHARGER DESIGN}

The charger for supercapacitor storage module should perform the following functions: to form the sinusoidal input current; to separate the network and the load galvanically; to charge the storage with direct or pulsating current.

To form the sinusoidal input current, the power factor corrector is required. The basic circuit of PFC [10] is quite simple but it does not provide the acceptable values of total harmonic distortion (THD) of the input current. To improve the values of THD the multiphase topology of PFC is applied. The multiphase PFC may include an unlimited number of unified cells (phases) connected in parallel, which operate with some phase shift. The input current in this case is a sum of the currents of PFC cells and its ripples are smaller than in the basic single-phase topology.

Because of the intention to use the supercapacitors (which have maximal voltage $2.7 \mathrm{~V}$ [11]) as energy storages in the designed charger, the step-down transformer is required to decrease the input voltage and to isolate the network and the load galvanically.

To charge the supercapacitor storage with direct or pulsating current, it is necessary to use the converter, which should meet the following requirements:
1) the availability of the input inductor, which forms the continuous current, consumed from the network;

2) the possibility of soft start and soft regulation of the input current;

3) the possibility of the transformer integration into the structure of the converter.

Table I shows the compliance of the converters of different types with the above mentioned requirements.

According to Table I, it may be concluded that the most appropriate converter types for the considered task are SEPIC and Cuk converters. The analysis of these types of converters [12] showed that the SEPIC converter has lower input current ripples and better controllability than the Cuk converter. Therefore, it is preferable to choose SEPIC as basic topology for designing the charger cell.

Let us calculate the parameters of charger cells.

The main circuit of the SEPIC converter is shown in Fig. 2.

TABLE I

COMPLIANCE OF THE CONVERTERS WITH THE SPECIFIED REQUIREMENTS

\begin{tabular}{|l|c|c|c|}
\hline \multirow{2}{*}{ Converter Type } & \multicolumn{3}{|c|}{ Requirements } \\
\cline { 2 - 4 } & 1 & 2 & 3 \\
\hline Buck & - & + & $+/-$ \\
\hline Boost & + & - & - \\
\hline Buck-boost & - & + & + \\
\hline SEPIC & + & + & + \\
\hline Cuk & + & + & + \\
\hline
\end{tabular}

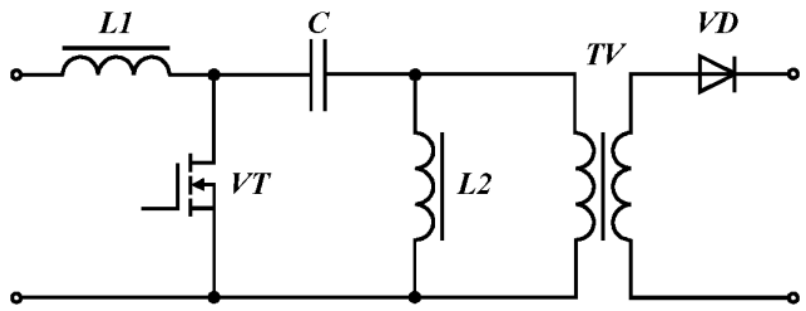

Fig. 2. The main circuit of the SEPIC converter.

The dimensions of the SEPIC converter are mainly determined by inductors $L_{1}, L_{2}$ and transformer TV. The dimensions of the transformer increase proportionally to the power, which is why the total dimensions of the cells' transformers may be considered as constant.

The dimensions of the inductor are proportional to the value of its inductance $L$ and to the square of the bias current $I_{02}$.

The inductance of $L_{1}$ is

$$
L_{1}=\frac{E_{\text {peak }}}{I_{\text {peak(c) }} f} \gamma,
$$

where $E_{\text {peak }}$ is peak voltage of electrical network and

$I_{\text {peak(c) }}$ is peak value of the cell current.

The inductance $L_{2}$ is calculated from the condition of discontinuous current mode in inductors [13], [14]

$$
L_{2}<\frac{L_{1} U_{\text {out }}}{n U_{\text {in }}}
$$

where $n$ is transformer ratio of TV. 
The capacitance $C$ is calculated from the condition of the resonant frequency $\omega_{\mathrm{r}}$, defined by reactive elements $C, L_{1}, L_{2}$, should be significantly higher than the frequency of the network $\omega_{\mathrm{g}}$.

$$
\omega_{\mathrm{r}}=\frac{1}{\sqrt{C\left(L_{1}+L_{2}\right)}}>>\omega_{\mathrm{g}} .
$$

Other elements of the SEPIC converter are calculated by common formulas.

Based on the given relations, the parameters of a two-phase transformerless charger designed on $300 \mathrm{~W}, 220 \mathrm{~V}, 50 \mathrm{~Hz}$ were calculated. The frequency of each converter cell $f=100 \mathrm{KHz}$, the duty cycle $\gamma=0.5$ with phase shift $180^{\circ}$, $L_{1}=700 \mathrm{mH}, L_{2}=3 \mathrm{mH}, C_{1}=50 \mathrm{nF}$.

The circuit of the charger is shown in Fig. 3.

The simulation models of a two-phase charger and a charger cell created in MATLAB Simulink, are shown in Fig. 4. The input current form and the current of the cells in large scale are shown in Fig. 5.

As shown in Fig. 5(a), the input current has some ripples, explained by nonlinearity of the real current form of the cell shown in Fig. 5(b) in a large scale.

In case of using the two-phase structure of the charger, the value of total harmonic distortion (THD) of input current amounts to $7 \%$, which provides the value of the power factor $>99 \%$. Therefore, even a two-phase charger can provide excellent electromagnetic compatibility with the network in the above mode. The high-frequency ripples can be additionally decreased by installing the input small power $L C$ filter, which helps to improve the power factor.

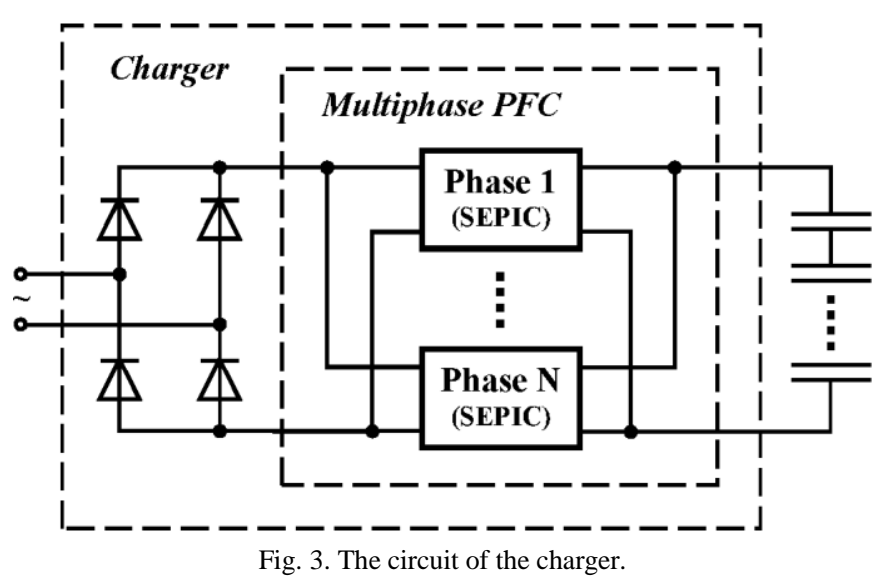

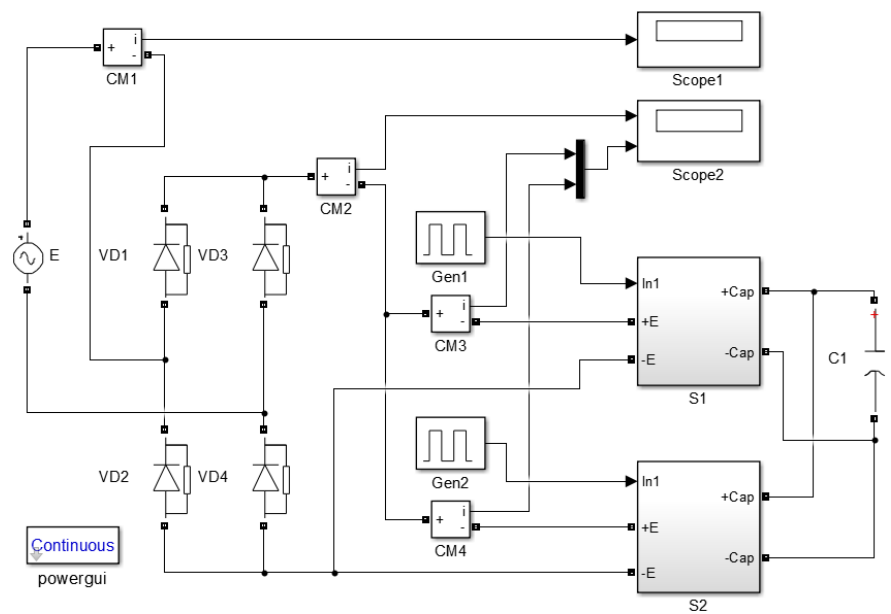

a)

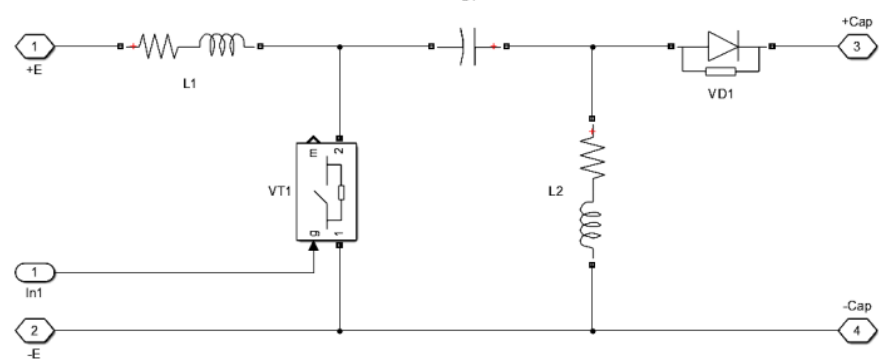

b)

Fig. 4. a) The multiphase charger model; b) one cell model.
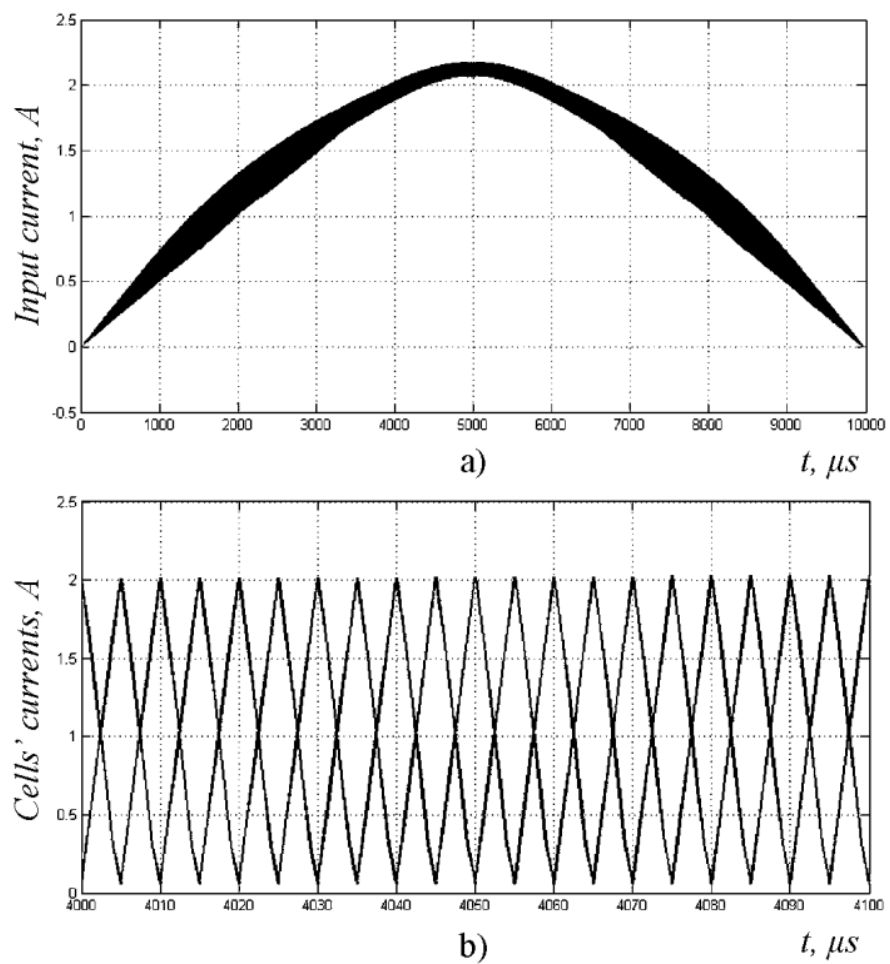

Fig. 5. a) The input current form; b) the cells' currents in large scale. 


\section{THE ENERgy Storage DESIGN}

The circuit topology of the energy storage for the power supply is suggested in Fig. 6.

The base of the energy storage is the supercapacitor battery, which includes $m$ supercapacitors connected in series. In this specific case, the main criterion for the choice of supercapacitor type is not the capacitance but the equivalent series resistance $(E S R)$, which should be as small as possible. The analysis showed that the decrease of supercapacitor ESR is accompanied by the increase of its capacitance [11]. Therefore, the choice of supercapacitor type with appropriate $E S R$ ensures the required capacity for micro resistance welding, which is not really so high.

The particularity of the suggested circuit is the principle of equalizing the voltages on the supercapacitors during their charge. The currents through the supercapacitors are equal. The variation of the supercapacitors' parameters leads to nonsimultaneity of their charging processes. For example, let $C_{\text {scap } 1}$ be charged first. Then, the recuperation cell A1 of the supercapacitor $C_{\text {scap } 1}$ starts operating. The A1 switches on after triggering the comparator DA1 and continues to operate until the supercapacitor $C_{\text {scap } 1}$ gets discharged. The power transistor VT1 of the cell A1 is controlled by PWM controller DA2. In this way the energy from $C_{\text {scap1 }}$ returns through the converter to the circuit of the input filter, the charge level of $C_{\text {scap1 }}$ stays constant and other supercapacitors continue their charging. After all the supercapacitors get completely charged, the signal of charging process stop is formed on the output of the logic element DD1. The input charger interrupts its operation and the energy stops being consumed from the network. Thus, the equalizing of charging processes of supercapacitors is provided.

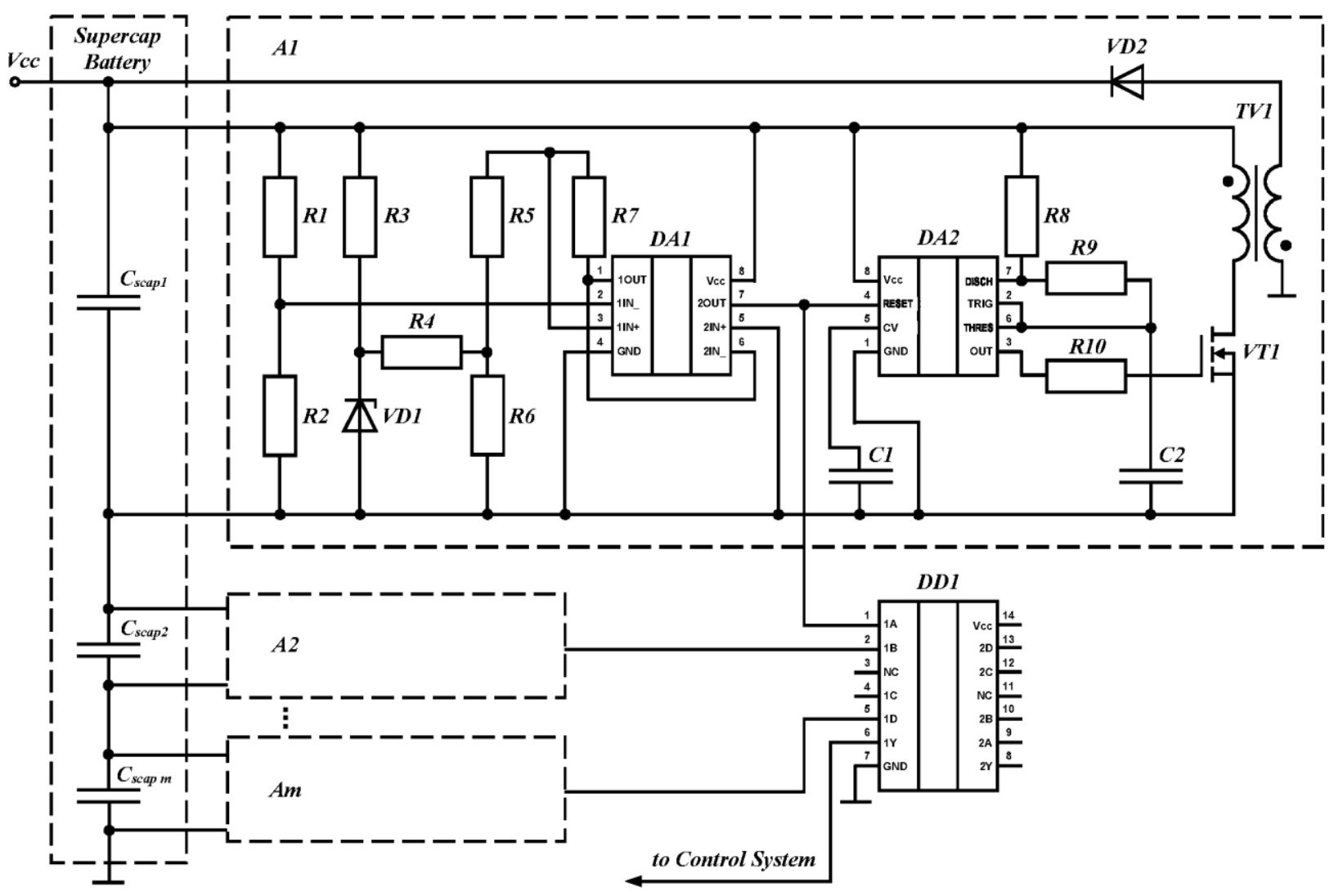

Fig. 6. The energy storage circuit.

\section{V.THE OUTPut GENERATOR OF WeLDING PULSES}

Now, let us consider the circuit of the output generator of welding pulses. To provide high value of welding current in load (up to thousands of amperes) and its high controllability, the most expedient solution seems to construct the output generator as a transistor converter of multicell type (Fig. 7). As the basis of the converter cell, the buck topology is chosen (Fig. 8).

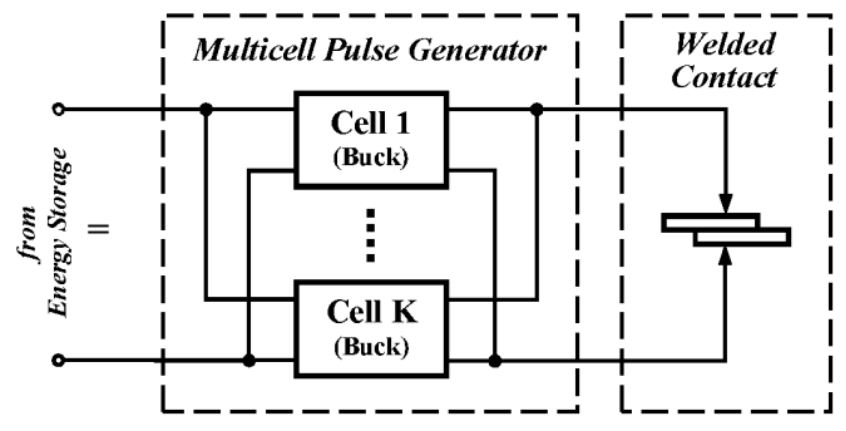

Fig. 7. The circuit of the output generator of welding pulses. 


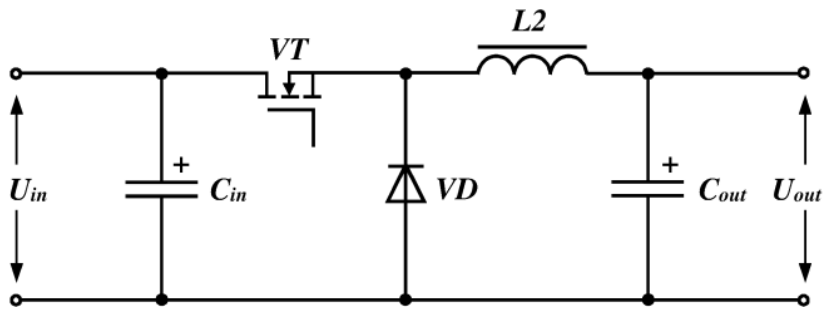

Fig. 8. The classical circuit of buck converter.

Because of high values of welding current, there are substantial energy losses on the converter elements. The bulk of the losses are located on reverse diodes of the cells (Fig. 8). The voltage drop on the open p-n-junction of a diode usually amounts to $1.2 \mathrm{~V}$ to $1.4 \mathrm{~V}$, in HEXFRED it is about $2.1 \mathrm{~V}$. The problem may be partially solved by using Schottky diodes, which have the forward voltage fall in the range of $0.4 \mathrm{~V}$ to $0.7 \mathrm{~V}$. However, the particularity of micro resistance welding consists in low output voltage (several volts or lower), and under these conditions the relative value of the energy losses on the circuit components increases. Therefore, the most effective solution may be the use of synchronous MOSFET transistors instead of the reverse diodes (Fig. 9) [15].

The ideal gate signal waveforms of VT1 and VT2 (Fig. 9) are shown in Fig. 10. The dead-times between VT1 and VT2 pulses are used to prevent the shoot-through. During the deadtime, the inductor current continues flowing through the internal body diode of VT2. When the gate signal of VT2 is high, the inductor current flows through VT2.

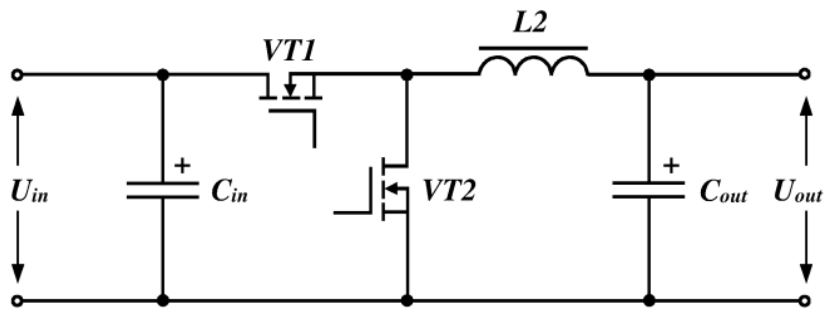

Fig. 9. Buck-converter circuit with the synchronous transistor.

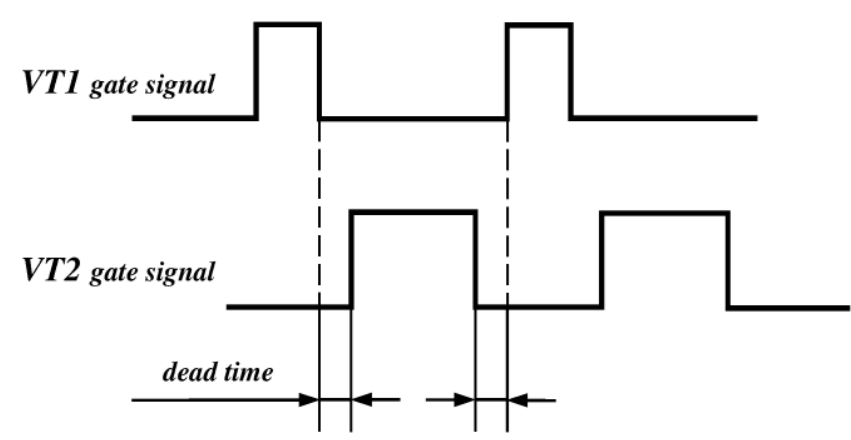

Fig. 10. Gate signal waveforms in VT1 and VT2 in buck converter with the synchronous transistor.

Synchronous buck topology provides better efficiency than standard buck converter because the on-resistance $R_{\mathrm{DS}(\mathrm{on})}$ of VT2 is in the milliohm range [15].

These considerations are confirmed by calculations with typical parameters. Let us study, how the maximal possible level of energy losses depends on the output current in the traditional buck converter circuit (Fig. 8) and the circuit with synchronous transistor (Fig. 9).

For the calculations, the following data are used (Table II).

TABLE II

DATA FOR CALCULATIONS OF ENERGY LOSSES

\begin{tabular}{|c|c|c|c|}
\hline$U_{\text {in }}, \mathbf{V}$ & $\boldsymbol{U}_{\text {out }}, \mathbf{V}$ & $\boldsymbol{f}, \mathbf{k H z}$ & $\boldsymbol{t}_{\text {on }}, \boldsymbol{\mu s}$ \\
\hline 5 & 5 & 100 & 0.416 \\
\hline
\end{tabular}

The energy losses in the diode are calculated using the method below [16].

The losses in forward direction

$$
P_{\mathrm{fw}}=\frac{1}{2} \Delta U_{\mathrm{d}} I_{0},
$$

where

$I_{0}$ the average value of rectified current through the diode;

$\Delta U_{\mathrm{d}}$ the voltage drop on the diode at a given value of output current.

The losses in reverse direction

$$
P_{\mathrm{rw}}=\frac{1}{2} U_{\mathrm{rw}} I_{\mathrm{rw}}
$$

where $U_{\mathrm{rw}}, I_{\mathrm{rw}}$ is reverse voltage and current in diode.

Dynamic losses in the diode

$$
P_{\mathrm{dyn}}=\frac{1}{2} U_{\mathrm{rw}} I_{0} f \tau_{\mathrm{h}}
$$

where

$f$ switching frequency;

$\tau_{\mathrm{h}}$ effective lifetime of holes in a diode.

Thus, the total energy losses in the diode can be calculated by the formula

$$
P=P_{\mathrm{fw}}+P_{\mathrm{rw}}+P_{\mathrm{dyn}} .
$$

The energy losses in the transistor are calculated using the following procedure.

The static energy losses

$$
P_{\mathrm{st}}=I_{\mathrm{d}}^{2} R_{\mathrm{DS}(\text { on })} \gamma
$$

where

$I_{\mathrm{d}}$ the current during the conduction period;

$R_{\mathrm{DS}(\text { on) }}$ open channel resistance of the transistor;

$\gamma$ the duty cycle of pulses.

The dynamic energy losses, considering the reverse current in opposite diode in the "hard" switch

$$
P_{\text {sw }}=U_{\text {in }} f\left(I_{\text {out }} t_{\mathrm{a}}+0.5 Q_{\mathrm{rr}}\right),
$$

where

$U_{\text {in }}$ input voltage;

$I_{\text {out }}$ output current;

$t_{\mathrm{a}}$ the part of reverse recovery time (approximately equals to on-time of transistor);

$Q_{\mathrm{rr}}$ reverse recovery charge.

The formula for calculating the total energy losses in the transistor

$$
P=P_{\mathrm{st}}+P_{\mathrm{sw}}
$$


As a result of calculations the values of energy losses in both circuits for different values of currents are obtained and the characteristic dependences are built (Fig. 11).

The characteristics show that energy losses in the circuit with a diode are higher than in the circuit with a synchronous transistor in the whole range of the current values.

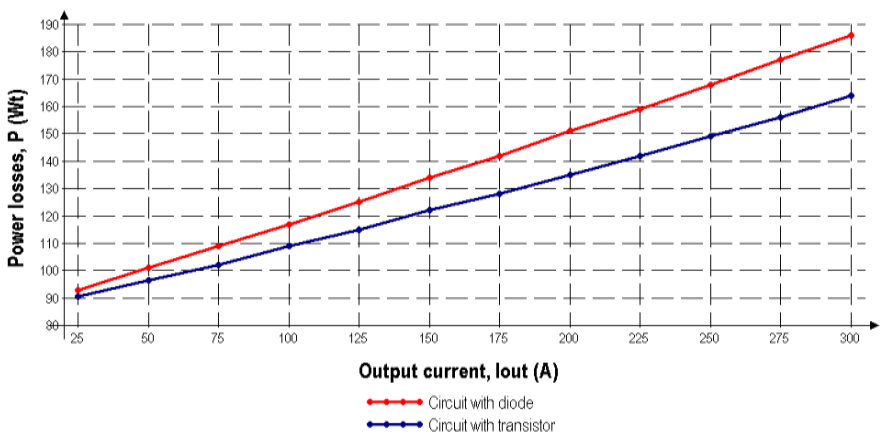

Fig. 11. Power losses in the circuits with diode and transistor depending on the output current.

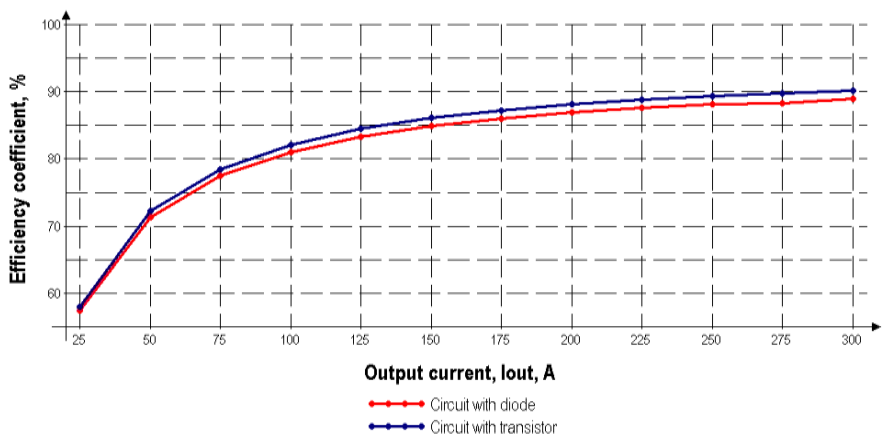

Fig. 12. The dependence of the efficiency of both circuits on the current.

In addition, while the current increases, the energy losses in both circuits are growing, but the overall efficiency of the circuits is growing as well (Fig. 12).

\section{CONCLUSION}

The study confirmed the effectiveness of the suggested circuit solutions for designing the main blocks of the power supply for micro resistance welding.

The multiphase principle of PFC construction and energy storage topology of the charger provide high quality of the input current form and the power factor value $>99 \%$.

The suggested circuit for the energy storage provides simultaneous charging of a number of supercapacitors with automatic equalizing of the voltages on each supercapacitor.

The use of synchronous transistors instead of the reverse diodes in the buck converters of the output generator cells provides the increase of energy efficiency of the power supply.

\section{ACKNOWLEDGMENT}

This research was supported by the grant No. 0116U006924 from the Ministry of Education and Science of Ukraine.

\section{REFERENCES}

[1] P. S. Safronov, I. V. Bondarenko, O. F. Bondarenko, V. M. Sydorets, and D. V. Kucherenko, "Increase of Electromagnetic Compatibility of Power Supplies for Resistance Welding," Technical Electrodynamics, no. 5, pp. 89-91, 2014. (in Ukrainian).

[2] Yu. E. Paerand, Yu. V. Bondarenko, and A. F. Bondarenko, "The reshapers of current impulses for the contact welding," Tekhnologiya $i$ konstruirovaniye v elektronnoy apparature, no. 3, pp. 25-30, 2008. (in Russian). [Online]. Available: www.tkea.com.ua/tkea/2008/3_2008/st_06.htm

[3] M. Salem, "Control and Power Supply for Resistance Spot Welding (RSW)," 2011. [Online]. Available: http://ir.lib.uwo.ca/etd/130/

[4] O. F. Bondarenko, P. S. Safronov, I. V. Bondarenko, and V. M. Sydorets, "Direct energy and energy storage circuit topologies of DC power supplies for micro resistance welding," 2014 IEEE 34th International Scientific Conference on Electronics and Nanotechnology (ELNANO), Apr. $\quad 2014, \quad$ pp. 468-471. https://doi.org/10.1109/elnano.2014.6873431

[5] C. A. Gallo, F. L. Tofoli, and J. A. Correa Pinto, "Two-Stage Isolated Switch-Mode Power Supply With High Efficiency and High Input Power Factor," IEEE Transactions on Industrial Electronics, vol. 57, no. 11, pp. 3754-3766, 2010. https://doi.org/10.1109/tie.2010.2041735

[6] H. Wang, S. Dusmez, and A. Khaligh, "Design considerations for a level-2 on-board PEV charger based on interleaved boost PFC and LLC resonant converters," 2013 IEEE Transportation Electrification Conference and Expo (ITEC), Jun. 2013, pp. 1-8. https://doi.org/10.1109/itec.2013.6574508

[7] O. F. Bondarenko, I. V. Bondarenko, P. S. Safronov, and V. M. Sydorets, "Effective circuit topology of DC power supply for micro resistance welding," 2014 IEEE International Conference on Intelligent Energy and Power Systems (IEPS), Jun. 2014, pp. 68-70. https://doi.org/10.1109/ieps.2014.6874204

[8] D. Kuzin, T. Khyzhniak, and O. Bondarenko, "Power quality improvement in single-phase power supplies for resistance welding," 2016 International Conference on Electronics and Information Technology (EIT), May 2016. pp. 30-34. https://doi.org/10.1109/iceait.2016.7500985

[9] I. V. Bondarenko, "Multicell-type Transistor Converter with Combined Continuous and Pulse Control for Micro Resistance Welding," $\mathrm{PhD}$ thesis, Kyiv, p. 148, 2012. (in Ukrainian).

[10] B. Singh, B. N. Singh, A. Chandra, K. Al-Haddad, A. Pandey, and D. P. Kothari, "A review of single-phase improved power quality ac $\sim \mathrm{dc}$ converters," IEEE Transactions on Industrial Electronics, vol. 50, no. 5, pp. 962-981, Oct. 2003. https://doi.org/10.1109/tie.2003.817609

[11] Product Comparison Matrix - Doc. 3000489.2, Maxwell Technologies Inc. [Online]. Available: http://www.maxwell.com/images/documents/Product_Comparison_Matr ix_3000489_2.pdf

[12] J. Dunia and B. M. M. Mwinyiwiwa, "Performance Comparison between CUK and SEPIC Converters for Maximum Power Point Tracking Using Incremental Conductance Technique in Solar Power Applications," International Journal of Electrical, Computer, Energetic, Electronic and Communication Engineering, vol. 7, no. 12, pp. 16381643, 2013. [Online]. Available: scholar.waset.org/1999.5/9996707.

[13] D. S. L. Simonetti, J. Sebastian, F. S. dos Reis, and J. Uceda, "Design criteria for SEPIC and Cuk converters as power factor preregulators in discontinuous conduction mode," Proceedings of the 1992 International Conference on Industrial Electronics, Control, Instrumentation, and Automation, pp. 283-288. https://doi.org/10.1109/iecon.1992.254619

[14] C. H. Chan and M. H. Pong, "Input current analysis of interleaved boost converters operating in discontinuous-inductor-curent mode," PESC97. Record 28th Annual IEEE Power Electronics Specialists Conference. Formerly Power Conditioning Specialists Conference 1970-71. Power Processing and Electronic Specialists Conference 1972, vol. 1, pp. 392 398. https://doi.org/10.1109/pesc.1997.616754

[15] H. Nguyen, "Design, Analysis and Implementation of Multiphase Synchronous Buck DC-DC Converter for Transportable Processor," M.S. thesis, Virginia Polytechnic Institute and State University, Blacksburg, Virginia, 2004, p. 98.

[16] A. Kolpakov, "Features of thermal calculation of pulse power links," Komponenty i tehnologii, no. 1, 2002. (in Russian). [Online]. Available: http://www.kit-e.ru/assets/files/pdf/2002_01_46.pdf 


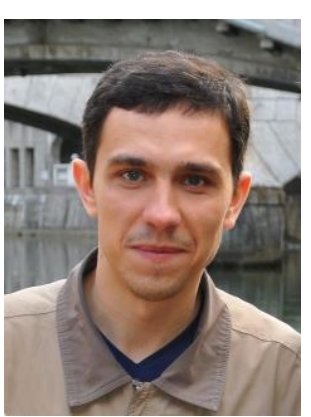

Oleksandr Bondarenko received the BSc degree in 2002 and Dipl.-Ing. in electronics in 2003 from Donbas Mining and Metallurgical Institute (Alchevsk, Ukraine). He defended his $\mathrm{PhD}$ thesis on power converters in 2008

$\mathrm{He}$ is currently a postdoctoral researcher and an Associate Professor with the Department of Industrial Electronics, National Technical University of Ukraine "Igor Sikorsky Kyiv Polytechnic Institute". Previously he has been a lab assistant, an assistant lecturer, a lecturer, an Associate Professor with Donbas State Technical University. His scientific interests include electronic engineering, resistance welding, electrotechnology.

$\mathrm{He}$ is an IEEE member. He was awarded the scholarship of Cabinet of Ministers of Ukraine, scholarship of Igor Sikorsky Kyiv Polytechnic Institute "Young teacher-researcher", and diploma from National Academy of Sciences of Ukraine for scientific work and inventions.

Postal address: Department of Industrial Electronics, Igor Sikorsky Kyiv Polytechnic Institute, 16/9 Yanhelia Akademika str., 03056, Kyiv, Ukraine. E-mail: bondarenkoaf@gmail.com.

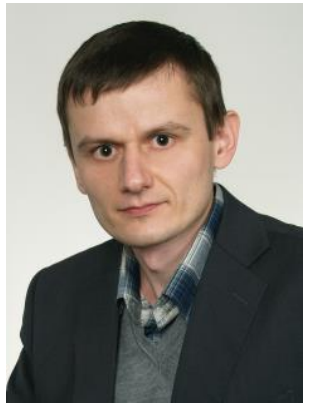

Ievgen Verbytskyi received the BSc degree in 2005 and MSc degree in electronics in 2007 from National Technical University of Ukraine "Kyiv Polytechnic Institute". He defended his $\mathrm{PhD}$ thesis on power converters in 2013.

$\mathrm{He}$ is currently an Associate Professor with the Department of Industrial Electronics, National Technical University of Ukraine "Igor Sikorsky Kyiv Polytechnic Institute". Previously he has been an engineer with the State Kyiv Design Bureau "Luch". His scientific interests include design of electric power converters, analysis and synthesis of control systems.

$\mathrm{He}$ is an IEEE member. He was awarded the scholarship of Igor Sikorsky Kyiv Polytechnic Institute "Young teacher-researcher" for scientific work and inventions.

Postal address: Department of Industrial Electronics, Igor Sikorsky Kyiv Polytechnic Institute, 16/9 Yanhelia Akademika str., 03056, Kyiv, Ukraine. E-mail: verbytskyi.ievgen@gmail.com

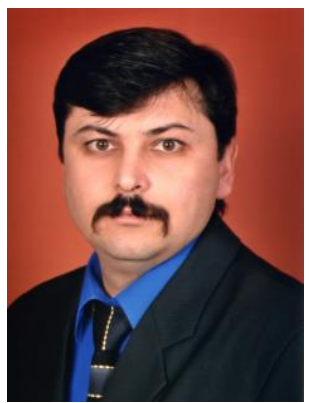

Vadym Prokopets received the Dipl. ing. in physics in 1996 from Taras Shevchenko National University of Kyiv and defended his $\mathrm{PhD}$ thesis on physics and mathematics in 2005.

$\mathrm{He}$ is currently an Associate Professor with the Department of Optics, Taras Shevchenko National University of Kyiv. Previously he has been an engineer and an Assistant Lecturer. His scientific interests are electrical engineering, automation of optical and electrical measurements, spectroellipsometry.

Postal address: Department of Optics, Taras Shevchenko National University of Kyiv, 4 Hlushkova Ave., 03127, Kyiv, Ukraine.

E-mail: vadym.prokopets@gmail.com

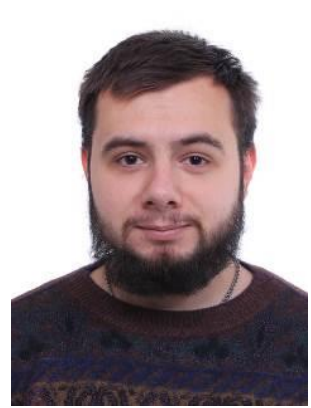

Kaloshyn Oleksandr received the BSc degree in 2013 and Dipl. ing. in electronics in 2014 from Donbas State Technical University (Alchevsk, Ukraine).

$\mathrm{He}$ is currently a $\mathrm{PhD}$ student with the Department of Industrial Electronics, National Technical University of Ukraine "Igor Sikorsky Kyiv Polytechnic Institute". His scientific interests are electronic engineering, reliability of device operation.

$\mathrm{He}$ is an IEEE member.

Postal address: Department of Industrial Electronics, Igor Sikorsky Kyiv Polytechnic Institute, 16/9 Yanhelia Akademika str., 03056, Kyiv, Ukraine.

E-mail: kaloshyn.oleksandr@gmail.com

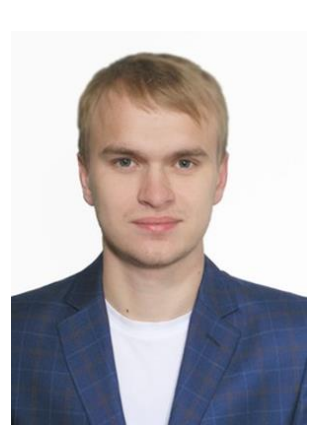

Denis Spitsyn received the BSc degree from National Technical University of Ukraine "Kyiv Polytechnic Institute" in 2016.

$\mathrm{He}$ is currently a master student with the Department of Industrial Electronics, National Technical University of Ukraine "Igor Sikorsky Kyiv Polytechnic Institute". His scientific interests are electrical and electronic engineering, control and systems engineering, power supplies and electrotechnology.

Postal address: Department of Industrial Electronics, Igor Sikorsky Kyiv Polytechnic Institute, 16/9 Yanhelia Akademika str., 03056, E-mail: spitsyndenys@gmail.com Kyiv, Ukraine.

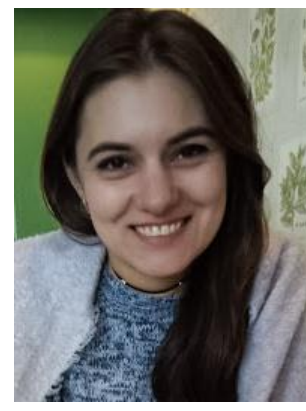

Tetiana Ryzhakova received the BSc degree in 2015 and the MSc degree in electronics in 2017 from National Technical University of Ukraine "Kyiv Polytechnic Institute".

She is currently a PhD student with the Department of Industrial Electronics, National Technical University of Ukraine "Igor Sikorsky Kyiv Polytechnic Institute". Her scientific interests are semiconductor power converters for resistance welding, energy storages.

She is a member of IEEE and Public organization "Lady Science".

Postal address: Department of Industrial Electronics, Igor Sikorsky Kyiv Polytechnic Institute, 16/9 Yanhelia Akademika str., 03056, Kyiv, Ukraine.

E-mail: ryzhakova.tetiana@gmail.com

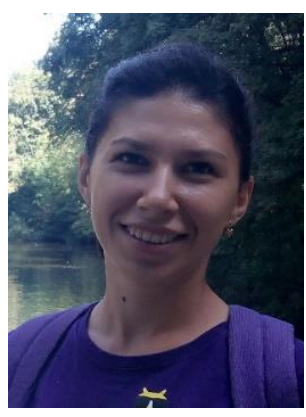

Yuliia Kozhushko received the BSc degree in 2015 and MSc degree in electronics in 2017 from National Technical University of Ukraine "Kyiv Polytechnic Institute".

She is currently a $\mathrm{PhD}$ student with the Department of Industrial Electronics, National Technical University of Ukraine "Igor Sikorsky Kyiv Polytechnic Institute". Her scientific interests are semiconductor power converters for resistance welding, energy storages.

She is a member of IEEE and Public organization "Lady Science".

Postal address: Department of Industrial Electronics, Igor Sikorsky Kyiv Polytechnic Institute, 16/9 Yanhelia Akademika str., 03056, Kyiv, Ukraine.

E-mail: kozhushko_yullia@ukr.net 